\title{
A World of Possibilities: The Place of Feasibility in Political Theory
}

\author{
Eva Erman ${ }^{1}$ (D) Niklas Möller ${ }^{2}$
}

Published online: 9 January 2019

(C) The Author(s) 2019

\begin{abstract}
Although the discussion about feasibility in political theory is still in its infancy, some important progress has been made in the last years to advance our understanding. In this paper, we intend to make a contribution to this growing literature by investigating the proper place of feasibility considerations in political theory. A motivating force behind this study is a suspicion that many presumptions made about feasibility in several current debates - such as that between practice-independence and practice-dependence, ideal and non-ideal theory, and political moralism and political realism - are too rigid and underestimate the numerous different ways in which feasibility concerns may enter into our theorizing. To chisel out this feasibility space, our aim is to suggest two metatheoretical constraints on normative political principles as intuitively plausible, the so-called 'fitness constraint' and the 'functional constraint', through which we elucidate five central aspects for determining proper feasibility constraints of an account in political theory.
\end{abstract}

Keywords Feasibility $\cdot$ Functional constraint $\cdot$ Fitness constraint $\cdot$ Possibility

In recent years we have witnessed an intensified discussion in political philosophy about the usefulness of normative political theories. Doubt has been thrown against traditional or mainstream political theory, which is accused of being useless since it recommends normative political principles that do not guide action in the real world. While different kinds of theories have been subject to this criticism-ranging from theories of global justice to theories of political legitimacy and democracy - a shared concern is that these theories are useless because they have

Eva Erman

eva.erman@statsvet.su.se

https://www.statsvet.su.se/eva_erman

Niklas Möller

niklas.moller@philosophy.su.se

1 Department of Political Science, Stockholm University, Stockholm, Sweden

2 Department of Philosophy, Stockholm University, Stockholm, Sweden 
not taken sufficiently seriously the many different ways that our current social and political practices delimit our normative political principles. For example, in the justice literature, practice-dependent theorists and non-ideal theorists have insisted that actual practices put methodological constraints on principles of justice (Sangiovanni 2008, 2016; Ronzoni 2009; Mills 2005; Farrelly 2007) as well as epistemological constraints (Sangiovanni 2008, 2016; James 2005, 2012; Banai et al. 2011). In the literature on democracy, likewise, pragmatist-influenced political theorists have argued that our practices put linguistic constraints on principles of democracy (Mouffe 1999, 2000; Norval 2006, 2009; Tully 1989; Fossen 2013). And in the literature on political legitimacy, political realists have asserted that principles of political legitimacy are delimited by political constraints, such as the constitutive features of politics (Rossi and Sleat 2014; Rossi 2013; Jubb and Rossi 2015; Jubb 2015a). We have tried to show elsewhere that the constraints suggested in these debates are often flawed or too strong (Erman and Möller 2013, 2014, 2015a, b, 2017, 2018). However, this does not take away the initial concern that pointed the above critics of mainstream political theory to a larger focus on social and political practices in the first place, namely, the idea that normative political principles should be feasible to be useful. It is this concern about feasibility in normative political theory that is the topic of the present paper.

Although the discussion about feasibility in political theory is still in its infancy, some important progress has been made in the last years to advance our understanding (Lawford-Smith 2013; Gilabert and Lawford-Smith 2012; Gilabert 2011, 2012; Wiens 2012, 2015; Southwood 2016; Southwood and Wiens 2016; Southwood 2016; see also Brennan and Pettit 2005; Brennan and Southwood 2007; Cohen 2009; Räikkä 1998). In this paper, we intend to contribute to this growing literature by investigating the proper place of feasibility considerations in political theory. A motivating force behind this study is a suspicion that many presumptions made about feasibility in the debates between practiceindependence and practice-dependence, between ideal and non-ideal theory, and between political moralism and political realism are too rigid and underestimate the available feasibility space, i.e. the numerous different ways in which feasibility concerns may enter into our theorizing. To chisel out this feasibility space, our aim is to suggest two metatheoretical constraints on normative political principles as intuitively plausible - the so-called 'fitness constraint' and the 'functional constraint' - through which we elucidate five central aspects for determining proper feasibility constraints of an account in political theory.

In developing these arguments, the paper unfolds in five sections. First, we briefly present the main conceptual and normative concerns addressed in the philosophical literature on feasibility. Thereafter, we outline the general characteristics of the two metatheoretical constraints. In the 'Three Aspects of the Functional Constraint and Feasibility' and 'Two Aspects of the Fitness Constraint and Feasibility' sections, we analyze five aspects of these constraints of relevance for feasibility. The 'Conclusion' section concludes. 


\section{Feasibility: A Conceptual Framework}

Before presenting our two metatheoretical constraints and discussing their feasibility consequences, let us start by putting feasibility in context. There is no consensus in the debate as to how the very concept of feasibility should be applied. Indeed, beyond the broad lexical answers such as being able to do or carry out something, it is doubtful that the question 'what is feasibility?' can be given a meaningful answer without a clear sense of what the consequences of feasibility (or lack thereof) are supposed to entail. Thus, how feasibility is understood depends on the different roles feasibility claims play in political theory. As we understand it, the basic idea is a more demanding constraint on normative theory than the classical 'ought implies can' proviso. Whereas the 'ought implies can' proviso filters out from the set of viable normative accounts those that for some reason or other cannot be realized-it is either ontologically or epistemologically impossible to follow the dictums of the account - the role of (in)feasibility considerations is to act as an additional filter. This requirement is captured by something along the lines of Nicholas Southwood's 'Ought-implies-feasible' proviso:

(OF) An agent $\mathrm{X}$ ought to realize a state of affairs $\mathrm{O}$ only if it is feasible for X to realize O. (Southwood 2016, p. 9; see also Southwood and Wiens 2016, p. 3043; Brennan and Southwood 2007) ${ }^{1}$

Southwood's proviso captures two important features of feasibility claims in normative theory. First, feasibility claims are agent-relative: it may be feasible for 29-yearold Adam to run the marathon under $4 \mathrm{~h}$, but not for 92-year-old Eve. Secondly, an obligation is conditioned on feasibility: it is necessary, but not sufficient, that it is feasible to realize a state of affairs. This fits well with the overall trend in the debate that the discussion is directed at feasibility as a qualitative aspect, as opposed to a

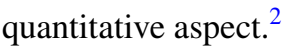

However, the proviso leaves out several qualifications important for making feasibility claims more precise. Since a potential (and in our diagnosis very actual) source of confusion in the feasibility debate relates to the lack of clarity as to what, more exactly is claimed, let us use Pablo Gilabert and Holly Lawford-Smith's helpful schema to clarify what a feasibility claim involves:

(F) It is feasible for $\mathrm{X}$ to $\varphi$ to bring about $\mathrm{O}$ in $\mathrm{Z}$

On this analysis, claims about feasibility involve a four-place predicate about what a given agent $X$ (which also may be a collective agent such as an institution) can do (a set of actions $\varphi$ ) to achieve a state of affairs $O$ in a given context $Z$, where the context itself also includes feasibility-affecting considerations (Gilabert and Lawford-Smith 2012, p. 812). A virtue of this schema is that it makes explicit the basic

\footnotetext{
1 'Agent' does not necessarily (and in political theory not even typically) entail a single person, but can be a group of persons, an institution and the like.

2 An exception here is Gilabert and Lawford-Smith (2012), whose second aspect of feasibility (see below in main text) clearly has that function.
} 
components of feasibility and thus renders immediately problematic the oversimplification and lack of clarity too often present in political theory, where most of the four components of the predicate are left unspecified in overarching claims such as 'Principle P is not feasible'. In particular, the sought context is almost never properly specified when critical claims about the infeasibility of mainstream political theory are made. When, for example, political realists make feasibility objections, the context may be as unspecified as 'the political domain' which indeed is a vague and unclear context. And even when it is specified that the sought context is some reasonable liberal society in 'the foreseeable future', it often remains unclear how that it to be interpreted. ${ }^{3}$

Another important aspect of the notion of feasibility in the schema above is the set of actions sought to bring about an outcome, which suggests an intentional component. In line with other theorists, we find it plausible to assume that the concept of feasibility applies only to the (possible) realization of states of affairs through intentional actions by agents (Southwood and Wiens 2016, p. 3041, n. 6). Natural events giving rise to certain states of affairs thus fall outside its domain of application and so it would not be meaningful to ask whether heavy rainfall today is feasible or infeasible.

So far we have treated conceptual form and assumed role of feasibility in normative theory. Turning to the content of feasibility, theorists agree that the feasibility of a sought (e.g. ideal) state of affairs depends on whether or not there is a trajectory leading to it from the present state of affairs, i.e. whether or not there is an accessible path of actions that we can take to arrive at the sought state of affairs from our starting-point (Gilabert and Lawford-Smith 2012, p. 813). The disagreement begins when we consider what should count as 'accessible'. Some theorists argue that mere possibility suffices (Gheaus 2013); others claim that the possibility must also be probable (Lawford-Smith 2013); yet others hold that questions of desirability figure into what is feasible and not (Räikkä 1998). ${ }^{4}$

In their influential analysis of feasibility, Pablo Gilabert and Holly LawfordSmith (2012) argue for a two-pronged analysis of feasibility, where feasibility in the first sense has to do with mere possibility (can the sought state be reached?) and the second has to do with the likelihood of reaching it (how probable is it given that we try?). They connect these two senses of feasibility to two types of constraints, hard and soft. Hard constraints are those that cannot be lifted, those that will 'always be constraints', such as metaphysical, logical and nomological constraints (Gilabert and

\footnotetext{
3 'Foreseeable' is indeed a weasel word allowing for many interpretations, since some claim that epistemic uncertainties are overwhelming no matter how small step into the future our thoughts wander.

4 The list is not complete. An additional example is stability, i.e. that a sought state of affairs must be relatively stable to be feasible (Cohen 2009, pp. 56-57; Rawls 1999, pp. 440-441; Brennan and Pettit 2005 , p. 264). Another recent example is feasibility as rational-volitional capacity, which is explicated as 'the capacity to decide to perform the act on the basis of believing that she ought to do so', 'the capacity to try to perform the act', and 'the capacity not to give up (trying to perform the act)' (Southwood 2016, pp. 14-16).
} 
Lawford-Smith 2012, p. 813). ${ }^{5}$ They thus tell us what is logically impossible as well as what is excluded given the laws of nature, and determine feasibility in the possibility-sense. Soft constraints, on the other hand, are malleable and thus subject to dynamic variation; examples include cultural, institutional, economic, psychological and motivational constraints (Gilabert and Lawford-Smith 2012, p. 814). They do not strictly speaking exclude a state of affairs, Gilabert and Lawford-Smith argue; instead, they make various possible states of affairs more or less likely to be realized.

Whereas the distinction between hard and soft constraints largely has been taken as reasonable in the literature (but see e.g. Wiens 2015 for a criticism), a more controversial issue has concerned which notions of possibility and probability should be used in feasibility contexts. On Gilabert and Lawford-Smith's analysis, feasibility (in the latter, 'soft', sense) is a function of the probability of bringing about a state of affairs conditional upon trying (2012, p. 815). In their view, using merely an unconditional probability would entail a 'cynical realism' (2012, p. 817). If people (indeed, easily) can give money to famine relief, at little cost to themselves, the fact (if a fact) that they are not motivated to do so does not entail that it is infeasible to them. David Estlund $(2011,2014,2016)$ similarly argues that motivational deficiencies do not entail infeasibility: 'being unable to bring oneself to do something [apart from in certain pathological circumstances] does not entail being unable to do it' (2016, p. 353). David Wiens argues against this position, claiming that there are non-trivial cases where the fact that a person cannot motivate herself to act in a certain way entails that she cannot in fact act in that way. In other words, there is a hard constraint against her acting in the way in question (Wiens 2015, 2018). A reasonable notion of feasibility, Wiens concludes, must utilize a more restricted notion of possibility.

The connection between feasibility and desirability is also a controversial issue in the literature. Some theorists argue that feasibility has a normative element, where the 'moral costs' of the social arrangements necessary for reaching a state of affairs may render it infeasible (Räikkä 1998; Miller 2008). Others have argued that a non-moralized concept of feasibility is useful because it "permits us to see clearly at which points in our normative analysis our feasibility judgements, as opposed to our desirability judgements, are doing the work' (Wiens 2015, p. 456; see also Gilabert and LawfordSmith 2012; Cohen 2001). The two questions then interconnect when we make judgments about what ought to be done or what obligations we actually have. By coupling a conceptual framework with a normative account, we may analyze different trajectories by testing which paths towards a desirable state of affairs are accessible in view of different constraints. In political theory, such an analysis is not merely an evaluative exercise since we want our theories to be action-guiding in some sense. It is also a prescriptive exercise with the aim of generating political judgments about what we ought to do

\footnotetext{
5 Lawford-Smith further distinguishes between what she calls 'time-insensitive' and 'time-sensitive' hard constraints. The former are those that are usually referred to in the literature on feasibility, notably, those that will always be constraints, such as the laws of nature. The latter, however, are those constraints that delimit what is impossible now but may not be so in the future, such as certain biological constraints (Lawford-Smith 2013, p. 253).
} 
under current conditions and what obligations we have (Gilabert and Lawford-Smith 2012, p. 818).

In our view, the above disagreements about how to understand feasibility directly reflects the heterogeneity of normative theory in general and political theory in particular. Particular normative accounts sorting under the umbrella term 'political theory' can have a myriad of different aims, contexts and delimitations, and we think that there are no general answers to give about the above considerations in abstract from these many aims and contexts. Thus, given certain aims, there are good reasons for either position in the above debates. For example, the distinction between hard and soft constraints is certainly illuminating. Still, it may be argued that how to apply the distinction remains unclear exactly where it matters to political theory. Take psychology and institutional design, which are categorized as soft constraints on Gilabert and Lawford-Smith's analysis (Gilabert and Lawford-Smith 2012, p. 813). It seems reasonable to assume that there are 'hard' constraints in these areas as well: some psychological aspects and ways of designing institutions are merely logically, but not practically, possible to change; we just do not know which. Similarly with various notions of possibility and probability; while there seems to be clear cases where we do, with Estlund and Gilabert and Lawford-Smith, want to say that following a principle is feasible even though people are not sufficiently motivated to do so, the possibility of actually making people sufficiently motivated clearly seems to be relevant for feasibility, especially in political theory. And, lastly, while it no doubt seems true that for reasons of internal coherence, there are limits to how much an account for which, say, autonomy is paramount can sacrifice people's autonomy to reach what the account takes to be the ideal state of affairs, there are also good reasons for treating questions of feasibility and desirability as conceptually independent.

In other words, we do not think that there is one clear question of feasibility to be answered but many. Whether a prescriptive principle is construed assuming soft and/or hard constraints, how exactly to spell out the accessibility idea and whether desirability is totally distinct from or part of feasibility, are all substantial matters, part and parcel of the account that is developed. In particular, it depends on the context of the particular theory. Consequently, we think that a fruitful way forward is not to try to settle one substantial account of feasibility for the domain of political theory, but to elucidate what contextual concerns matter for the particular theory at hand. Specifically, our suggestion is that this will be helpfully elucidated by two metatheoretical constraints: a constraint in relation to what an intended normative political principle is aimed to regulate (the functional constraint), and a constraint in relation to how it fits together with the other principles, values and states of affairs which are endorsed in the account (the fitness constraint). To these two metatheoretical constraints we now turn.

\section{Two Constraints on Normative Political Principles}

We agree with the critics of mainstream political theory mentioned in the introduction about the claim that more focus should be put on how principles are constrained by the typically non-ideal circumstances in which we find ourselves. Only by doing 
so could we get a more systematic grasp of the proper place of feasibility considerations in normative theorizing. At the same time, we have argued elsewhere that the suggested ways in which actual social and political practices are said to constrain normative political principles - e.g. in the form of methodological, epistemological, linguistic and political constraints-are unreasonably strong. This investigation has resulted in an overall skepticism about general yet substantial constraints on political theories. Due to the many different, equally sensible, aims of theorists in the debates about justice, democracy and political legitimacy, we have found no support for any general yet substantial 'musts' for political theories. If there are any general constraints, they must be abstract and open enough to be compatible with virtually any potential aim in political theory, but still entail substantial delimitations when the context so demands. With regard to feasibility, it seems reasonable to us that a normative political principle may in some circumstances be justified without taking any feasibility considerations into account, whereas it may have to respect a rigid set of practical constraints in other circumstances. To mention a case at one end of the spectrum: if the theorist investigates a principle of justice for a society of moral angels, she may assume that there will be absolutely no weakness of will or limited altruist problems that the theory needs to navigate. If, on the other hand, the principle should guide a group of actual persons trapped on a desert island this very moment, the theory will operate with a much more demanding (and inflexible) set of constraints which may include, for example, the motivational set of the persons involved and the material resources available to them.

Below, we discuss two metatheoretical constraints which respond to these desiderata, that we find intuitively plausible: what we will call the functional constraint and the fitness constraint. The functional constraint is an explicitly context-dependent constraint concerned with what a principle or account is intended to regulate or do, whereas the fitness constraint is a requirement on the relation between the commitments made in an account. Being basically a coherence condition, the latter is often seen as a 'trivial' or 'self-evident' constraint with little practical import for political theorizing. However, we will argue that it has implications for feasibility that are often ignored and therefore deserves more attention than many theorists acknowledge. In the rest of this section, we describe the general features of these two constraints, before focusing on the specific aspects that are relevant for feasibility considerations in the remaining two sections. There we will argue that the functional constraint involves three aspects of importance for feasibility: the principle-kind aspect, the practice-kind aspect, and the temporal aspect, while the fitness constraint involves two aspects of importance for feasibility: the dynamic aspect and the non-binary aspect.

\section{The Functional Constraint}

In its most abstract form, the functional constraint is the requirement that the guiding principles of a normative account must be appropriate for what the account aims to do, that is, what the suggested principles are supposed to regulate, and within what limits they are supposed to do so. To begin with, a guiding principle is a principle 
of some kind. Generally in normative theory, it is not uncommon to ask what we should do, full stop. According to some theorists, what we morally ought to do in a situation is the question of what we should do, all things considered (Hare 1952; Gibbard 2003), whereas other theorists take the moral ought to have a more limited scope (Foot 1959; Jackson 1998). In political philosophy, however, the output of a normative account is typically not a principle which aims to determine what we should do, all things considered. ${ }^{6}$ Instead, theorists commonly argue for a principle of justice, a principle of fairness, a principle of democracy, a principle of legitimacy or the like. These kinds of principles are at the very least conceptually distinct. Even when Rawls argues for 'justice as fairness', he is not arguing that justice means fairness, but (somewhat crudely) that a justified principle of justice is a principle that takes fairness as its main constituent.

But the functional constraint not only requires a specification with regard to the kind of principle, it also requires that the principle is appropriate for what it intends to regulate, that is, the practice or domain to which it is supposed to be applied (e.g. the basic institutions of a society). And the domain of application may vary. For example, a principle of justice may be intended for the distribution of goods between family members, the local football team, the municipality, the nation state or a world government. Depending on the features of the domain, different principles may be justified. Even if a principle of strict distributive equality would be just, say, between siblings of a young age, that same principle might not be justified for a world government. Consequently, when developing a normative account, the intended practice or domain plays a central part in shaping the governing principles. We will return to these aspects of the functional constraint but let us first lay out the general features of the fitness constraint.

\section{The Fitness Constraint}

Whereas the functional constraint is an explicitly context-dependent requirement relating to the role the account is intended to play in normative political theory, the fitness constraint is a requirement on the relationship among the commitments made within an account. In its most abstract form, the fitness constraint captures the idea that a normative political principle of an account should fit together with the other principles, values and states of affairs which are (or should be) endorsed in the account. If a suggested principle of justice does not fit together with the fundamental moral principles and values subscribed to in the account, or with

\footnotetext{
${ }^{6}$ What we should do, all things considered, is here taken to be equivalent to 'what we should do, taking into account all the things that matter', or, if we switch to reason-talk, 'what we have conclusive reason to do' (see, e.g. Chang 2004, p. 1). In the current debate, when we aim to form 'all-things-considered political judgments' (Gilabert and Lawford-Smith 2012, p. 809), the scope is typically narrower. If we ask ourselves what is 'demanded by justice', all things considered, what we get is what is just to do, or differently put, what we should do, given all things that are relevant to justice. But whether that is equivalent with what we should do, all things considered, depends on whether justice trumps all other concerns. For some theorists, such as Rawls, the answer seems to be in the affirmative. For others, such as Cohen (2008, 2009), it is clearly not.
} 
other political principles or values endorsed by it, the account is justificatory deficient. If, on the other hand, the endorsed principles, values and particular claims in the account fit well with each other, the suggested principle of the account is justificatory strengthened.

To those committed to coherentism or the method of reflective equilibrium, broadly construed, this introductory description of the fitness constraint might seem trivial or at least wholly uncontroversial. But contrary to this first impression (and as we will show below), the fitness constraint has consequences overlooked in the debate on feasibility. Moreover, the fitness constraint is neutral to central epistemological and methodological controversies: first, the fitness constraint on our construal is neutral vis-à-vis foundationalism and coherentism in epistemology; and second, it is neutral vis-à-vis choice of methodology (reflective equilibrium or other).

Consider first the general form of the fitness constraint. While the fitness constraint indeed bears a close resemblance to coherence accounts in epistemology, it is on our interpretation orthogonal to both coherentism and foundationalism as full-blown theories of justification. It applies whether or not you believe there to be such a thing as a set of fundamental beliefs that is self-justified, that is, justified in ways other than through its fit with other beliefs. Also for the foundationalist's account to be justified, her set of claims needs to be internally coherent. If not, either what she took to be self-evident (or otherwise self-justified) is in fact false, or (perhaps more probable) some of the other claims need to go. This is not to say, of course, that the foundationalist or the coherentist would not have additional demands on justification; they typically do. Our point here is merely that both camps must reasonably acknowledge the constraint on their theories that all commitments they make fit together.

Moreover, although the fitness constraint is in accordance with the method of reflective equilibrium (Rawls 1951, 1999), we do not think it is correctly described as a methodological constraint. Rather, it is compatible with virtually any methodology. For sure, in order to fulfill the fitness constraint, the political theorist formulating and developing a normative account would have to engage in processes of introspection and modification of the set of commitments she takes to be part of the account. And such a process would typically consist of comparing the specific normative commitments about particular instances, principles and values, and revising these when there is a lack of fit between them. Still, such a process is not mandatory. It is perfectly conceivable, if not entirely probable, that the theorist just happens to formulate an account which at the stage of initial formulation already fulfills the fitness constraint, without utilizing the above process commonly described as reflective equilibrium. And in any case, we think it misleading to call a process of belief revision a 'method', since that would imply something more substantive than the formal requirement that the fitness constraint sets out to be (Erman and Möller 2018).

With this general outline of the two suggested constraints on the table, let us now examine what we see as their main components and what implications they have for feasibility considerations in normative political theorizing. 


\section{Three Aspects of the Functional Constraint and Feasibility}

Since the functional constraint focuses on the teleological dimension of an account, i.e. what it aims to regulate, and under what circumstances it aims to do so, there are many kinds of feasibility constraints that may come into play. In this section we will investigate the potential feasibility consequences of three central aspects of the functional constraint. One crucial aspect of the functional constraint is the requirement that a suggested principle or account is appropriate for what it aims to regulate or achieve. Henceforth, we call this the "principlekind' aspect. Secondly, a guiding principle is supposed to be applied to a particular practice (or domain). We call this the 'practice-kind' aspect. In addition to these two aspects, the functional constraint incorporates a third aspect, namely, the 'temporal' aspect, which specifies whether the guiding principle have a shortterm or a long-term aim. We discuss these three aspects under separate headings below and discuss their implications for feasibility.

\section{The Principle-Kind Aspect}

The principle-kind aspect has several consequences for what kind of feasibility considerations becomes appropriate. First, for a principle to be feasible, it must be able to be interpreted as a principle of the intended kind. If the sought principle is a principle of justice, it arguably cannot be a principle which suggests that all goods should be distributed to the persons who are born on a Monday, or something similarly arbitrary. Political realists, for example, refer to this kind of constraint when they - taking their cue from Bernard Williams's idea that 'might is not right' (1985)_argue that a legitimate order cannot be based only on power (Rossi and Sleat 2014; Jubb and Rossi 2015; Sleat 2010). The concept of legitimacy is simply not compatible with such an illegitimate order. Similarly, they argue that the fact that a principle of legitimacy should be understood as a political principle entails several feasibility constraints, notably that the context in which the suggested principles are justified must not assume agreement, since there is no political community in which the members are in agreement (Jubb 2015b; Sleat 2016).

Elsewhere, we have argued against this conclusion as a general conclusion against normative political principles (Erman and Möller 2015b, 2018). Although not every conceivable political order may reasonably count as legitimate, the claim that an account of legitimacy is not justified on the grounds that it uses a faulty concept of legitimacy typically does not cut very deep. In order to be effective, it must be an argument explaining what is faulty with the notion of legitimacy employed. And such an argument must go well beyond the conceptual domain, because if the only complaint against the account is that it utilizes the wrong label for its principle, little has been achieved. That said, if the aim of the theorist is to justify a political principle to guide our behavior in many present circumstances - as opposed to somewhere down the line-the principle-kind sets more substantial constraints (see 'The Temporal Aspect' section below). 
Second, the principle-kind aspect also decides how to interpret the feasibility constraints in a way that is seldom discussed in the debate, namely, in relation to assumed level of compliance. A common argument against ideal accounts in political philosophy is that the suggested principles are justified only if we assume that people comply with them, but that so-called full compliance is highly unlikely. The question of what compliance entails becomes more complicated, however, if we acknowledge that most principles are not intended to give allthings-considered guidance (Rawls's two principles being an exception; see fn. 6). Consequently, the fact that people do not or would not act in accordance with a certain principle of justice, does not necessarily mean that they are not complying with it. Perhaps there is another principle-say a principle of non-domination-which overrules this justice principle in a set of circumstances. Then the fact that it is highly unlikely that all people, at all times, would act in accordance with the principle of justice does not mean that they are not complying with it, if there are other reasons for action that, in the contexts in question, weigh stronger. This means that infeasibility charges against principles for which full (or something close to full) compliance figures in their justification may in some cases be too quick, even if the principle in question aims to give direct action-guidance.

Third, the principle-kind aspect also concerns whether the principle is intended to have direct or indirect application, that is, whether or not its function is directly action-guiding or 'merely' indirectly so (Farrelly 2007; Sen 2006). Many critics of mainstream political theory take feasibility to entail action-guidance: a feasible principle must guide action for its intended target practice. Moreover, this guidance is typically assumed to be direct, in the sense that it should be possible to act in accordance with the principle. While this demand seems reasonable on the surface, it neglects several indirect ways of guiding action. We perceive of at least two cases of indirect yet helpful guidance.

To start with, even a principle which is not, strictly speaking, applicable to a practice may be useful for that practice. In order to motivate this idea, we need only look at models in natural science. A model is by definition merely similar in important respects to the phenomenon of interest and includes some counterfactual assumptions and simplifications which set it apart from the real phenomenon. But a model of a power plant may still be helpful for, say, the design of a control system for the power plant. Similarly, in the case of politics, it seems to us that the very aim of more or less 'ideal' normative theories is to supply a model case for our actual society. Assuming features that no actual society may ever exemplify_-such as full compliance-might be seen exactly as a model of an actual society. Most ideal theorists use such counterfactual devices in order to conceptualize the upper limits for a just or legitimate society.

It is here important to note that endorsing 'indirect application' in this sense is compatible with endorsing (OF), the 'ought implies feasible' proviso, mentioned in the first section. A theorist developing an ideal account may acknowledge that the ideal principle argued for is indeed infeasible, and thus agree that we have no obligation to follow it. Still, grasping the case for the ideal principle may help us when developing principles which are directly action-guiding. 
To see how this may work, take the Vision Zero case in traffic safety. Given the sheer potential for accidents and statistical facts such that traffic is the most common cause of death for young adults, a principle saying that we ought to have no deaths in traffic seems infeasible indeed. ${ }^{7}$ Still, starting in Sweden in the 1990s, the vision to have no causalities in traffic has resulted in a revolutionary rethinking. For example, the main responsibility for traffic safety has shifted from the individual to the system, and the object of safety has shifted from avoiding accidents to avoiding casualties, so that the severity of an accident rather than accident prevention per se has come to the forefront. This has resulted in several safety improvements focusing on speed reduction, such as roundabouts, where the number of accidents has increased, but the severity has decreased significantly (Belin et al. 2012). Consequently, even ideals which are unattainable may guide action and motivate stakeholders (in this case traffic safety professionals) to act in order to come closer to the ideal.

\section{The Practice-Kind Aspect}

The practice-kind aspect-that a guiding principle is supposed to be applied to a particular practice - also has implications for feasibility, since a suggested principle must not only be a principle of the right kind, but also for the intended practice. Consider, for example, a principle for the just appointment to various positions in society. For some positions, such as the appointment of professors at a university, it seems reasonable to utilize the Rawlsian idea of positions open to all, with meritocratic concerns playing a major role. For other positions, say, the just appointment of a leader of a family business, meritocracy may perhaps justifiably play a less deciding role. It may be reasonable to consider family members, as long as their competence is above a certain threshold, even when they would not be among the best available candidates if judged purely on merit. For yet other positions, lottery or turn-taking may be a just principle of appointment.

Importantly, though, the practice-kind aspect involves a target flexibility that is often neglected in current debates, in particular among defenders of practicedependence, non-ideal theory, and political realism. One dimension of target flexibility deals with the criteria for a practice kind: what counts as belonging to a certain practice kind? By 'flexibility', we here mean two things. First, we refer to the fact that there are multiple arrangements qualifying as the practice in question. If the target practice is the family, for example, we may typically think of a unit consisting of two (different-sex) parents and, say, two children. But there are many deviations from this 'typical' nuclear family unit, both in relation to number of children and to adults in a parental capacity. Second, we refer to the fact that the 'borders' of the target practice usually are unclear or negotiable. Whereas it is wholly uncontroversial that two additional children do not turn a family into another kind of institution, other deviations from the paradigmatic family constitution is more a matter of negotiation. In many countries in the northern hemisphere, a family may consist

\footnotetext{
7 Of course, this is due to implicit practice-constraints (to be discussed in the next subsection in the main text): it would not be infeasible, for example, if we prohibited all person-traffic.
} 
of same-sex adults, or transgender persons, an arrangement that is much more controversial (and often explicitly forbidden) in other parts of the world. Similarly, in many countries families are seen as consisting of parents and (some of the) grandparents, i.e. covering more than two generations.

Another dimension of target flexibility deals with the issue of how potential deviations from the sought target practice should be handled. Let us assume, for example, that the aim of the theorist is to develop a theory of justice for the European Union. Suppose that the theorist finds that true justice would demand that the European Union were a fiscal union. But the European Union is not a fiscal union, and a critic could therefore argue that the theorist's principle, however justified for a fiscal union, cannot be a principle for the European Union. This line of argument to let the nature of the target practice play an essential role for principles of justice is common among proponents of practice-dependence (Sangiovanni 2008; Ronzoni 2009; James 2005).

The theorist has two basic ways of responding to this concern. First, she may contest the conceptual claim, arguing that even if changed to a fiscal union, it would still be the European Union. This option utilizes the second sense of 'flexibility' mentioned above, according to which the borders of the target practice are negotiable. Secondly, she may accept the current constitution of the European Union as a necessary constraint for her theory, acknowledging that her account cannot be an account for the European Union. Importantly, though, what the latter option entails is an open question that depends specifically on what function the account aims to fulfill. On the one hand, there may be many practical or pragmatic reasons for treating the current constitution of the European Union as a 'given', so that if her account entails the suggested changes, it cannot be the sought account. In such cases, the current constitution of the European Union becomes a direct feasibility constraint. One the other hand, the theorist may judge that if her account is not compatible with the target practice, so much the worse for the target practice. In other words, given her aim with the account, what matters might be that there is a possible arrangement playing the (approximate) role of the European Union in which justice may be upheld, not that the institution is constituted in the same way as the current European Union. ${ }^{8}$

Apart from target flexibility, the practice-kind aspect of the functional constraint also raises concerns with regard the limits of feasibility. When feasibility considerations are made in the current literature, it is typically the 'upper limit' that is discussed: if the suggested principles demand too much of people, the account is not feasible. But on our functional constraint, the question of a 'lower limit' is equally important. If an account of justice demands too little of people, the account is equally infeasible as an account of justice. Slavery is a good example. Rather than attempting to find a bar of 'justice' low enough to be compatible with the practice of slavery, abolishing the practice in its entirety seems to be the better alternative. Few theorists nowadays argue for slavery; but there is an interesting analogue in the

\footnotetext{
${ }^{8}$ In Erman and Möller (2018) we utilize an analogous argumentative strategy against the political realist claim that mainstream accounts cannot be political accounts since the political domain necessarily has certain properties (e.g. disagreement).
} 


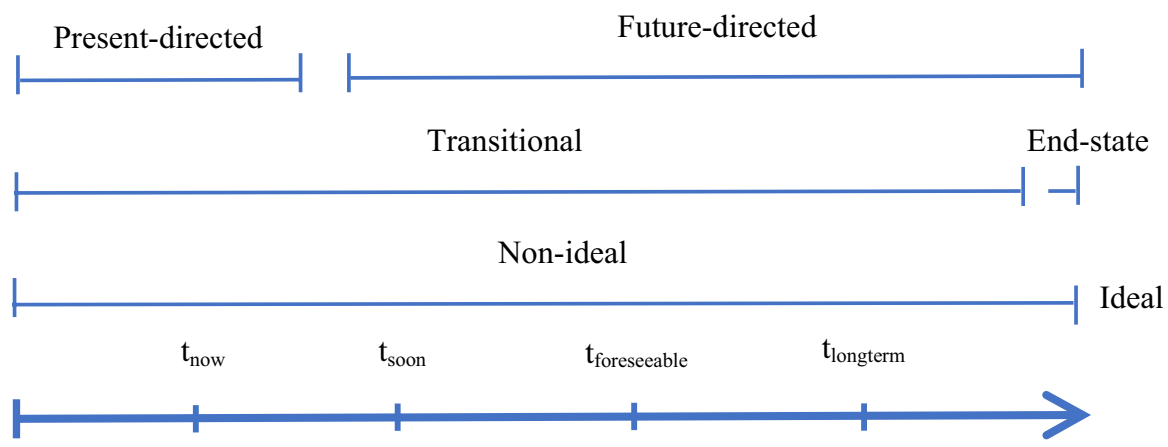

Fig. 1 Temporal varieties

contemporary just war theory debate, where some varieties of pacifism hold that war simply cannot be just (cf. Cady 1989; Brock 1998; Fox 2014).

\section{The Temporal Aspect}

A third aspect of the functional constraint is the temporal aspect. Indeed, whether or not a principle is feasible strongly depends on when the principle is supposed to come into effect. Many normative accounts in political theory are not primarily present-directed, i.e. directed at providing practical action-guidance for the present state of affairs; rather, they are future-directed in the sense that they have a more long-term aim. Rawls famously distinguished between ideal and non-ideal theories to mark the difference between theories that aim to justify a set of principles for perfect justice, and theories that aim to take us (closer) to that ideal via non-ideal principles (Rawls 1999). A similar distinction is often made between end-state theories and transitional theories (Valentini 2012, pp. 660-662; Sen 2006, 2009).

The binary form of the above distinctions may give the impression that there are only two kinds of temporal constraints: the now (non-ideal) or the later (ideal). But while similar, on closer scrutiny the distinctions are clearly distinct. As the figure below illustrates, the three distinctions carve up the timeline differently. Futuredirected accounts may be either transitional or end-state, and all of them may be non-ideal, if the ideal in question is infeasible (and if so, the ideal account is not on the timeline at all). Centrally, however, what is captured by the distinctions is in fact a continuous temporal dimension, in principle giving rise to countless different temporal feasibility constraints. ${ }^{9}$ To which temporal feasibility constraint a certain account has to conform thus depends on whether the account aims to regulate the here and now $\left(\mathrm{t}_{\text {now }}\right)$, a close temporal point $\left(\mathrm{t}_{\text {soon }}\right)$, a foreseeable future $\left(\mathrm{t}_{\text {foreseeable }}\right)$ or any number of other future cutting-points (Fig. 1).

\footnotetext{
9 Of course, it is theoretically possible, albeit highly unlikely, that the present constitutes the best possible state of affairs, so that whatever principle we abide by, things will only get worse. In that case, the 'now' and the end-state are the same point.
} 
Now, if the function of the principle is to regulate current state of affairs, the feasibility constraints are set by the present empirical context of the practice of the community, group or other entity which constitutes the target domain of the principle. For example, the present set of resources we have at our disposal, people as we are now with our present aims, desires and skillsets, will set limits to what is possible to achieve at present, and principles for today need to accommodate these facts. If the function of the principle is to regulate the end-state or ideal practice, however, the feasibility constraints are much more open-ended. The upper limits for feasibility are then given not by our presently available goods and resources, and people's present aims, desires and skillsets, but by what is possible to reach, given the present starting-point. Perhaps scientific discoveries and technological advances will enable us to fill all of our energy needs in a sustainable way and produce plenty of natural and social goods for all. Perhaps, given the right fostering, care-takers and societal arrangements, most people may develop levels of cognitive, emotive and social skills matched only by a small fraction of presently living people. If such possibilities are actual, there is room for a much more demanding set of principles of, say, justice or equality, than many critics of mainstream political theory have argued. ${ }^{10}$ If, on the other hand, on a societal level we have more or less reached our limits for empathy and abilities of giving and asking for reasons, and the set of natural and social goods can only marginally improve in the future, the upper limits of feasibility will not be far from those guiding present state of affairs.

Between these two end-points, however, there is an endless number of possible time frames which delimit the feasibility space for a guiding principle. ${ }^{11}$ Let us exemplify this continuum by considering a suitable principle of autonomy. A theorist whose goal is to develop an ideal account of autonomy may find it reasonable to assume that the critical mass of agents has the material and cognitive means enabling them to pursue a substantial set of potential projects, and given this assumption argue that autonomy is to be free to choose and to take responsibility for one's life choices. Such an account of autonomy may come with few feasibility constraints, apart from some permissive possibility conditions, for example, that the account should be compatible with the basic features of human nature as we know them as well as be possible to achieve with the status quo (Buchanan 2004; Gilabert and Lawford-Smith 2012).

Another theorist, who may or may not have formed a determined account of ideal autonomy, is interested in developing an account of autonomy on the domestic level (say, an account of autonomy for members of a particular community, neither excessively poor nor extremely prosperous) to be realized in the present. In such a case, her account must respect the present bulk and distribution of goods and abilities

\footnotetext{
$\overline{10}$ See Gilabert (2017) for a nice elaboration of this temporal variation. According to Gilabert's so-called 'dynamic approach' to justice, we should not only focus on what is immediately feasible because what is not feasible now may become so in the future if we take some steps to expand our political abilities, for example, through 'dynamic duties', i.e. duties which are not focused on achieving certain desirable outcomes under current conditions but rather on how to change those conditions so that the outcomes could become achievable (Gilabert 2017, pp. 119-121).

11 Unless, of course, in the implausible event that these two points coincide.
} 
to a much larger degree, which gives rise to a more demanding set of feasibility constraints.

A third theorist may set out to develop an account of autonomy applicable to her present society in the next century. In such a case, she may allow for a much greater independence in relation to present levels of goods and their distribution, the psychology and state of knowledge of the (mainly future) population, and even the conception of the society (many alternative societal arrangements are arguably possible in 100 years) to which the principle should be applied. Still, she would plausibly let the present state of affairs play a stronger constraining role than in the first, fully ideal case above. The twenty-second century is only three generations away, and so the leeway for changes that are slower to bring about is more limited than in the ideal or end-state principle case.

Recall that feasibility considerations are considerations about trajectory in all of these cases, about pointing to an accessible path of actions that can be taken to arrive at the desired state of affairs. It must thus be possible to move in incremental steps from the (typically less ideal) present state of affairs to the (more ideal) states that the principles directly regulate. This is not to say that the theorist, in order to justify her account, must demonstrate that the future world is reachable. Of course, if it can be shown that the world is not reachable from the present world, an account aiming to be directly applicable has problems. But as long as the case is inconclusive, as often is the case when it comes to human nature and empirical circumstances in the future, uncertainty about whether or not circumstances in which suggested principles are both applicable and justifiable are possible to reach within the constraints set by the temporal aspect is not sufficient to reject the account. ${ }^{12}$

\section{Two Aspects of the Fitness Constraint and Feasibility}

Let us move from the functional to the fitness constraint. Given its formal, non-substantial character, we believe that few theorists would reject the fitness constraint. Yet, its implications in practice are surprisingly underappreciated. In several current debates, arguments are often worked out as if justifications have a set direction. Consider, for example, the debate on ideal and non-ideal theory, in which non-ideal theorists insist that we defy the 'top down' strategy utilized by ideal theorists-starting with general higher-level principles - and instead work in a context-sensitive 'bottom up' manner when we theorize appropriate principles of justice (Mills 2005; Farrelly 2007). Likewise, in the debate on practice-independence and practice-dependence, practice-dependent theorists insist that the justification of a principle of justice is dependent on the nature of the practice it is intended to govern and that we may only get a proper understanding of this nature through a robust interpretive methodology (James 2005, 2012; Sangiovanni 2008, 2016; Ronzoni 2009; Rossi 2013).

\footnotetext{
12 A similar point is made by Christian Barry and Laura Valentini when they note that reasonable disagreement about the feasibility of principles is not sufficient to reject a principle (Barry and Valentini 2009, pp. 510-511).
} 
There is thus a tendency to assume that the endorsement of the proposition ' $q$ justifies p' would also imply the denial of its converse, i.e. that 'p justifies q'.

However, the fitness constraint puts a dynamic condition on the principle that the account sets out to justify. Any direction of justification, whether bottom up or top down, or a set of commitments on an equal level of prior justificatory force, is allowed. This is the case because the conditions of fitness concern the ways in which all relevant claims fit together in the account. Simply put, in order for the account to be justified, it must fit with the other claims on which the account is premised. If there appears to be tensions between different commitments of the account, regardless of other virtues, these must be resolved before the account may be considered justified. And the resolution may only be made in either of two fundamental ways: by abandoning at least one of the commitments in the account, or by showing that there actually is no tension after all (Erman and Möller 2018). We analyze this 'dynamic aspect' of the fitness constraint below, and its closely related 'non-binary' aspect, and discuss their implications for feasibility.

\section{The Dynamic Aspect}

The dynamic aspect suggests that different feasibility considerations may be appropriate for different principles within an account, depending on how the principles harmonize. Even a typical ideal account could comprise more or less ideal principles. For example, in line with the temporal aspect discussed above, a theory of justice may consist of a principle of justice which is construed under the constraint that it must be realizable within the long-term future and a higher-level moral principle of equal respect for persons that does not set out such feasibility demands. Similarly, a non-ideal account may consist of more or less realizable principles, for example, one regulating what justice requires under current socio-political conditions and given available resources, another aiming at reducing severe injustices. As dictated by the functional constraint, the appropriate feasibility considerations for each principle is dependent on what the principle is aimed to achieve. And there are no predetermined limits to functional variety within an account and how many principles it may incorporate, as long as the principles harmonize so that the fitness constraint is fulfilled. In a nutshell, this means that if an account includes an applied principle construed under demanding feasibility constraints and a more general higher-level principle construed under weaker or no feasibility constraints, the applied principle must be reasonable from the standpoint of the higher-level principle given the feasibility constraints assumed by the applied principle (and vice versa).

The dynamic aspect is easily overlooked in practice. According to Gilabert and Lawford-Smith, for example, the proper role of feasibility in political judgment is sketched in the form of a three-stage model. In a first stage (S1), core normative political principles (in their case, principles of justice) are formulated and justified. At this stage, they argue, only hard feasibility constraints are relevant. In the second (S2) and third stages (S3), we move from principles to their implementation. Here not only hard but also soft feasibility constraints are relevant. While the theorist in $\mathrm{S} 2$ assesses which institutional scheme best implements the principles from $\mathrm{S} 1$, she 
assesses the strategies of political reform that lead to the actual realization of this institutional scheme in S3 (Gilabert and Lawford-Smith 2012, pp. 819-820). One advantage with a model that distinguishes between these three stages, according to the authors, is that it avoids 'the mistake of assuming that feasibility assessments are uniform across stages, and that low feasibility at one stage simply translates into low feasibility at others' (2012, p. 821).

While we think this three-stage model sketches out one plausible method for developing an account, and certainly agree with the conclusion that it would be a mistake to assume that feasibility assessments must be uniform across stages, we contend that the fitness constraint allows for an even richer and more useful view of the proper place of feasibility in normative political theorizing. The fitness constraint does not demand that we structure our normative inquiry about what we ought to do in terms of a 'first-principles-then-implementation' strategy. To begin with, consider the work that the distinction between principles and implementation is supposed to do in the model. Implementation is premised on something to implement, and in the suggested model this is core principles of justice. The stage metaphor fits nicely into this picture, since we cannot reach the second stage without completing the first, and so on. But for the theorist, institutional schemes and strategies of political reform are typically theorized through the formulation of non-ideal or applied principles. And while the three-stage sequence is one way to go about to do so, it is not the only way. The fitness constraint may be fulfilled in other ways, and through other sequences.

Rather than a three-stage model, our two constraints suggest a more open model, consisting of one or more levels of application. How many levels of application an account includes, and which level of application the theorists start with (first stage) is an open question. For example, we may start with a formulation and justification of a principle of perfect justice (P2) to be applied to the basic structure of society, construed under hard constraints such as moderate scarcity, i.e. that 'natural and other resources are not so abundant that schemes of cooperation become superfluous, nor are conditions so harsh that fruitful ventures must inevitably break down' (Rawls 1999, p. 110). ${ }^{13}$ To give this principle additional justificatory support, we may then ask, in a second stage, whether this principle of justice harmonizes with a higher-level moral principle of some kind (P1), applicable to human beings directly and construed assuming no feasibility constraints. Thereafter, we may theorize nonideal principles of justice in view of P1 and P2, for example, one that assumes the soft constraint that people are not only able to act to achieve the desired state of affairs but are also potentially long term willing to access this path with the right incentives (P3), and another even more applied principle which assumes the soft constraint that people are able and sufficiently willing now with current resources (P4). With regard to feasibility, P2 would thus be false if it violated the hard constraints so that the path is actually not accessible, and P3 and P4 would be false if they violated the soft constraints. Once the account is in place, the theorist may pass

\footnotetext{
13 Indeed, moderate scarcity would presumably count as what Lawford-Smith calls a 'time-sensitive' hard constraint, i.e. a constraint that delimits what is impossible now but may not be so in the future (2013, p. 253).
} 
a political judgment about what ought to be done- that is, how to best meet the requirements of justice-by taking all principles of the account into consideration.

Hence, while the different principles of the account assume different feasibility constraints in our example, similar to Gilabert and Lawford-Smith's model, this need not take a three-stage form, which demands that we start with core principles of justice assuming certain hard constraints and then ask how they are best implemented given certain soft constraints. Apart from their suggested sequence, we can well imagine others, such as $\mathrm{P} 4-\mathrm{P} 3-\mathrm{P} 2-\mathrm{P} 1$. The crucial point from the perspective of the dynamic aspect is that it can be demonstrated that the principles on different levels of application fit together. ${ }^{14}$

\section{The Non-Binary Aspect}

Also the closely related 'non-binary' aspect of the fitness constraint raises important methodological questions, in particular for the debate on ideal and non-ideal theory in the justice literature. According to a widely accepted view-what we here call the 'binary view' of ideal and non-ideal theory-either one kind of theory is defended and the other is dismissed as flawed, or one of them is seen as necessarily prioritized. An example of the former dismissive version of the binary view is Charles Mills, who criticizes theories which utilize concepts and principles that are not based in an actual context for being fundamentally flawed (Mills 2005, pp. 173-175; see also Farrelly 2007; Galston 2010; Wiens 2012, 2015). The abstract and higher-level principles defended by ideal theorists ignore present injustices, according to Mills, and thereby lose the conceptual tools needed to capture what ought to be done. By abstracting away coercion and relations of structural domination and visualizing human agents in unrealistic ways through idealized capacities and institutions, ideal theories neglect how real agents and institutions function (Mills 2005, pp. 168-169).

An example of the latter priority version of the binary view is John Simmons, who argues that we must make use of normative ideals, because 'to dive into nonideal theory without an ideal theory in hand is simply to dive blind, to allow irrational free rein to the mere conviction of injustice and to eagerness for change of any sort' (Simmons 2010, p. 34; see Arvan 2014). Admittedly in a less colorful language, Rawls expresses the priority version as well: the reason we must begin with ideal theory is that it provides 'the only basis for the systematic grasp' of justice (Rawls 1999, p. 8). The nature and aim of perfect justice are more fundamental parts of the theory of justice, since a deeper understanding of justice 'can be gained in no other way' $(1999$, p. 8). The ideal part of the theory is also 'essential for the

\footnotetext{
${ }^{14}$ See Gilabert (2017) for a view that is compatible with ours. Here he emphasizes the non-sequential nature of theorizing the different components of a conception of social justice (Gilabert 2017, p. 111, n. 23).
} 
non-ideal part' since it sets up 'an aim to guide the course of social reform', which is the task for non-ideal theory (Rawls 1999, pp. 343, 215). ${ }^{15}$

Both versions of the binary view become overly strong, and thus unwarranted, on our account. Instead, the non-binary aspect of the fitness constraint implies that feasibility should be seen as a continuum of different constraints that we may put on an account. From this perspective, ideal and non-ideal becomes a relational matter. An account may be ideal in comparison with accounts that are narrower in scope and/or are construed under more demanding feasibility constraints, and non-ideal in relation to others, which are broader in scope and/or come with weaker feasibility constraints. We draw three conclusions from this: first, there are no grounds for dismissing either ideal or non-ideal theory in principle (see Valentini 2012); second, the non-binary aspect requires nothing in terms of priority, i.e. in terms of what one must do first; and third, it allows the theorist to limit her account to ideal or nonideal theory without there being anything wrong with the proposed account, as long as the fitness constraint (and the functional constraint) is satisfied.

That said, we believe that non-ideal theorists underestimate the essential role often played by basic values or higher-level principles when they defend 'non-ideal state A' over 'non-ideal state B'. This does not become clear from the examples often utilized in the literature, such as that we may judge which of two mountains is higher without knowledge about the highest mountain in the world, Mount Everest (Sen 2009). Such descriptive examples do not capture what we do when we make normative comparisons. If we consider tallness in relation to jockeys, i.e. those who ride horses in horse racing or steeplechase racing, we know that they cannot be too tall because then they will weigh too much. ${ }^{16}$ When we make comparative judgments about the tallness of jockeys, we will most likely use if not a full-fledged ideal theory about optimal height, at least some background values or higher-level principles about horse racing (Erman and Möller 2018, Ch. 7). If our suggested constraints are plausible, there might be cases where we do not have a full-fledged theory at our disposal, such as Rawls's two principles of justice, but only some underspecified values we consider fundamental when we think about the aims of a theory of justice (such as the values expressed through the veil of ignorance). In this situation, we might instead work from a number of different cases of injustice, say, by thinking about the justifications for different ways of opposing an unjust regime under the presumption of partial compliance. By considering numerous such non-ideal principles, we may become equipped to slowly move towards a deeper understanding of justice, and even a systematic grasp of the "nature and aims of a perfectly just society', pace Rawls (Rawls 1999, p. 8). As we discussed in the previous section, both justificatory directions lie open to the theorist under the fitness constraint.

\footnotetext{
15 While the binary view is the view that Rawls generally expresses, he seems at places to have a more cautious attitude. For even if we generally grant the soundness of the two (ideal) principles of justice for the purpose of setting up guidelines for non-ideal principles under less favorable conditions, they and their lexical order 'were not acknowledged with these situations in mind and so it is possible that they no longer hold' (Rawls 1999, p. 216).

16 Although the famous jockey Lester Piggott was unusually tall, measuring 173 centimetres, hence the nickname 'The Long Fellow'.
} 


\section{Conclusion}

Our aim in this paper has been to contribute to the growing literature on feasibility by investigating the proper place of feasibility considerations in political theory. We have suggested two metatheoretical constraints on normative political principles as intuitively plausible - the so-called 'fitness constraint' and the 'functional constraint' - through which we have elucidated five aspects of relevance for determining proper feasibility constraints in an account. Our analysis suggests that there is no general answer to which feasibility constraints are most appropriately tied to a normative political principle. Instead, the possibilities that lie open to the theorist with regard to feasibility constraints are almost endless, at least pre-theoretically, since they will depend on the context of the particular theory at hand (its aim, what practice it intends to regulate, its temporal horizon, and so on). Our hope is that these metatheoretical discussions will be seen as an initial step toward a broader dialogue about the proper place of feasibility considerations in normative political theory.

Acknowledgements The authors owe special thanks to the participants of conference 'Facts and Norms III: the indeterminacy between factual and normative judgements' held in Copenhagen (24-25 August 2017), in particular to Theresa Scavenius who organized it. We also thank the editors and anonymous referees of Res Publica for valuable comments. In addition, Eva Erman thanks the Swedish Research Council and Marianne and Marcus Wallenberg Foundation for the generous funding of her research.

Open Access This article is distributed under the terms of the Creative Commons Attribution 4.0 International License (http://creativecommons.org/licenses/by/4.0/), which permits unrestricted use, distribution, and reproduction in any medium, provided you give appropriate credit to the original author(s) and the source, provide a link to the Creative Commons license, and indicate if changes were made.

\section{References}

Arvan, Marcus. 2014. First Steps Toward a Nonideal Theory of Justice. Ethics \& Global Politics 7(3): 95-117.

Banai, Ayelet, Miriam Ronzoni, and Christian Schemmel. 2011. Global Social Justice: The Possibility of Social Justice Beyond States in a World of Overlapping Practices. In Social Justice, Global Dynamics: Theoretical and Empirical Perspectives, ed. A. Banai, M. Ronzoni, and C. Schemmel, 46-60. London: Routledge.

Barry, Christian, and Laura Valentini. 2009. Egalitarian Challenges to Global Egalitarianism: A Critique. Review of International Studies 35: 485-512.

Belin, Matts-Åke, Per Tillgren, and Evert Vedung. 2012. Vision Zero: A Road Safety Policy Innovation. International Journal of Injury Control and Safety Promotion 19(2): 171-179.

Brennan, Geoffrey, and Nicholas Southwood. 2007. Feasibility in Action and Attitude. In Hommage á Wlodek: Philosophical Papers Dedicated to Wlodek Rabinowicz, ed. T. Rønnow-Rasmussen, B. Petersson, J. Josefsson, and D. Egonsson. Lund: Philosophy Department at Lund University.

Brennan, Geoffrey, and Philip Pettit. 2005. The Feasibility Issue. In Oxford Handbook to Contemporary Philosophy, ed. F. Jackson and M. Smith, 258-297. Oxford: Oxford University Press.

Brock, Peter. 1998. Varieties of Pacifism: A Survey from Antiquity to the Outset of the Twentieth Century. Syracuse, NY: Syracuse University Press.

Buchanan, Allen. 2004. Justice, Legitimacy, and Self-Determination. Oxford: Oxford University Press.

Cady, Duane. 1989. From Warism to Pacifism. Philadelphia, PA: Temple University Press.

Chang, Ruth. 2004. All Things Considered. Philosophical Perspectives 18(1): 1-22. 
Cohen, G. A. 2001. Why Not Socialism? In Democratic Equality: What Went Wrong?, ed. E. Broadbent, 58-78. Toronto: University of Toronto Press.

Cohen, G. A. 2008. Rescuing Justice and Equality. Cambridge, MA: Harvard University Press.

Cohen, G. A. 2009. Why Not Socialism?. Princeton, NJ: Princeton University Press.

Erman, Eva, and Niklas Möller. 2013. Three Failed Charges Against Ideal Theory. Social Theory \& Practice 39(1): 19-44.

Erman, Eva, and Niklas Möller. 2014. Brandom and Political Philosophy. The Journal of Political Philosophy 22(4): 486-498.

Erman, Eva, and Niklas Möller. 2015a. What Not to Expect from the Pragmatic Turn in Political Theory. European Journal of Political Theory 14(2): 121-140.

Erman, Eva, and Niklas Möller. 2015b. Political Legitimacy in the Real Normative World: The Priority of Morality and the Autonomy of the Political. British Journal of Political Science 45(1): 215-223.

Erman, Eva, and Niklas Möller. 2017. Practice-Dependence and Epistemic Uncertainty. Journal of Global Ethics 13(2): 187-205.

Erman, Eva, and Niklas Möller. 2018. The Practical Turn in Political Theory. Edinburgh: Edinburgh University Press.

Estlund, David. 2011. Human Nature and the Limits (If Any) of Political Philosophy. Philosophy \& Public Affairs 39: 207-237.

Estlund, David. 2014. Utopophobia. Philosophy \& Public Affairs 42: 113-134.

Estlund, David. 2016. Reply to Wiens. European Journal of Political Theory 15(3): 353-362.

Farrelly, Colin. 2007. Justice in Ideal Theory: A Refutation. Political Studies 55: 844-864.

Foot, Philippa. 1959. Moral Beliefs. Proceedings of the Aristotelian Society 59: 83-104.

Fossen, Thomas. 2013. Taking Stances, Contesting Commitments: Political Legitimacy and the Pragmatic Turn. Journal of Political Philosophy 21: 426-450.

Fox, Michael Allen. 2014. Understanding Peace: A Comprehensive Introduction. New York/London: Routledge.

Galston, William. 2010. Realism in Political Theory. European Journal of Political Theory 9: 385-411.

Gheaus, Anca. 2013. The Feasibility Constraint on the Concept of Justice. The Philosophical Quarterly 63: 445-464.

Gibbard, Allan. 2003. Thinking How to Live. Cambridge, MA: Harvard University Press.

Gilabert, Pablo. 2011. Feasibility and Socialism. The Journal of Political Philosophy 19: 52-63.

Gilabert, Pablo. 2012. Comparative Assessments of Justice, Political Feasibility, and Ideal Theory. Ethical Theory \& Moral Practice 15: 39-56.

Gilabert, Pablo. 2017. Justice and Feasibility: A Dynamic Approach. In Political Utopias: Contemporary Debates, ed. M. Weber and K. Vallier, 95-126. Oxford: Oxford University Press.

Gilabert, Pablo, and Holly Lawford-Smith. 2012. Political Feasibility: A Conceptual Exploration. Political Studies 60: 809-825.

Hare, R. M. 1952. The Language of Morals. Oxford: Oxford University Press.

Jackson, Frank. 1998. From Ethics to Metaphysics: A Defence of Conceptual Analysis. Oxford: Oxford University Press.

James, Aron. 2005. Constructing Justice for Existing Practice: Rawls and the Status quo. Philosophy \& Public Affairs 33: 281-316.

James, Aron. 2012. Fairness in Practice: A Social Contract for a Global Economy. Oxford: Oxford University Press.

Jubb, Robert. 2015a. Playing Kant at the Court of King Arthur. Political Studies 63: 919-934.

Jubb, Robert. 2015b. The Real Value of Equality. Journal of Politics 77: 679-691.

Jubb, Robert, and Enzo Rossi. 2015. Political Norms and Moral Values: A Reply to Erman and Möller. Journal of Philosophical Research 40: 455-458.

Lawford-Smith, Holly. 2013. Understanding Political Feasibility. The Journal of Political Philosophy 21: 243-259.

Miller, David. 2008. Political Philosophy for Earthlings. In Political Theory: Methods and Approaches, ed. D. Leopold and M. Stears, 29-48. New York, NY: Oxford University Press.

Mills, Charles. 2005. 'Ideal Theory' as Ideology. Hypatia 20(3): 165-184.

Mouffe, Chantal. 1999. Deliberative Democracy or Agonistic Pluralism? Social Research 66: 745-758.

Mouffe, Chantal. 2000. The Democratic Paradox. London: Verso.

Norval, Aletta. 2006. Democratic Identification: A Wittgensteinian Approach. Political Theory 34: $229-255$.

Norval, Aletta. 2009. Democracy, Pluralization, and Voice. Ethics \& Global Politics 2: 297-320. 
Räikkä, Juha. 1998. The Feasibility Condition in Political Theory. The Journal of Political Philosophy 6: 27-40.

Rawls, John. 1951. Outline of a Decision Procedure for Ethics. Philosophical Review 60: 177-197.

Rawls, John. 1999. A Theory of Justice. 2nd edn. Cambridge, MA: The Belknap Press of Harvard University Press.

Ronzoni, Miriam. 2009. The Global Order: A Case of Background Injustice? A Practice-Dependent Account. Philosophy \& Public Affairs 37: 229-256.

Rossi, Enzo. 2013. Consensus, Compromise, Justice and Legitimacy. Critical Review of International Social and Political Philosophy 16: 557-572.

Rossi, Enzo, and Matt Sleat. 2014. Realism in Normative Political Theory. Philosophy Compass 9: 689-701.

Sangiovanni, Andrea. 2008. Justice and the Priority of Politics to Morality. The Journal of Political Philosophy 16: 137-164.

Sangiovanni, Andrea. 2016. How Practices Matter. The Journal of Political Philosophy 24: 3-23.

Sen, Amartya. 2006. What Do We Want from a Theory of Justice. Journal of Philosophy 103: 215-238.

Sen, Amartya. 2009. The Idea of Justice. London: Allen LanePenguin.

Simmons, John. 2010. Ideal and Nonideal Theory. Philosophy \& Public Affairs 38: 5-36.

Sleat, Matt. 2010. Bernard Williams and the Possibility of a Realist Political Theory. European Journal of Political Theory 9: 485-503.

Sleat, Matt. 2016. What Is a Political Value? Political Philosophy and Fidelity to Reality. Social Philosophy and Policy 33(1-2): 252-272.

Southwood, Nicholas. 2016. Does 'Ought' Imply 'Feasible'? Philosophy \& Public Affairs 44: 7-45.

Southwood, Nicholas, and David Wiens. 2016. Actual' Does Not Imply 'Feasible. Philosophical Studies 173: 3037-3060.

Tully, James. 1989. Wittgenstein and Political Philosophy: Understanding Practices of Critical Reflection. Political Theory 17: 172-204.

Valentini, Laura. 2012. Ideal vs. Non-ideal Theory: A Conceptual Map. Philosophy Compass 7/9: 654-664.

Wiens, David. 2012. Prescribing Institutions Without Ideal Theory. The Journal of Political Philosophy 20: 45-70.

Wiens, David. 2015. Political Ideals and the Feasibility Frontier. Economics and Philosophy 31: 447-477.

Wiens, David. 2018. Rejoinder to Estlund (manuscript).

Williams, Bernard. 1985. Ethics and the Limits of Philosophy. Cambridge, MA: Harvard University Press.

Publisher's Note Springer Nature remains neutral with regard to jurisdictional claims in published maps and institutional affiliations. 